\title{
A water balance approach to assess rainwater availability potential in urban areas: the case of Beijing, China
}

\author{
Wen Liu, Weiping Chen, Chi Peng, Laosheng Wu and Yuguo Qian
}

\begin{abstract}
Rainwater is an underutilized water resource that has become more important in recent years; due to severe water logging and water shortage in cities. The evaluation of rainwater harvesting potential is of fundamental importance in planning rainwater harvesting systems and management policies. In this study, we used minute-interval rainfall data and the water mass balance method coupling urban hydrological processes to assess the annual rainwater availability potential (RAP) of different underlying surfaces in the urban areas of Beijing (inside the 5th Ring Road). The estimated total RAP was 154.49 million $\mathrm{m}^{3}$ in 2013 . About $53 \%$ of rainwater could be effectively harvested for use, among which the rooftops had the highest harvesting ratio of $70 \%$, and contributed about half of the total RAP. Indirect use of rainwater can be achieved through infiltration facilities, of which concave green land construction and porous brick pavement can increase the amount of rainfall that infiltrates into

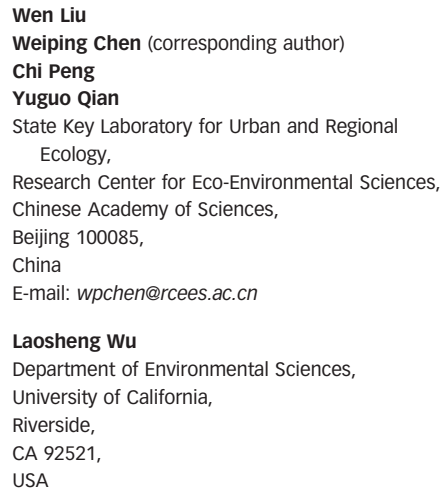
the soil by $18.89 \%$ and $55.69 \%$, respectively. Rainwater harvesting and utilization could serve as a

Key words | green land, infiltration facilities, rainwater availability potential (RAP), rainwater harvesting, rooftop

\section{INTRODUCTION}

Urban water scarcity is becoming worse due to population growth and economic development, degradation of the surrounding water environment, changes of the natural hydrological cycle due to land use and land cover change in urban areas, and global climate change (Konrad \& Booth 2005; Aladenola \& Adeboye 20I0; Huong \& Pathirana 20I3). Increasing water availability is one of the important challenges for sustainability of urban areas, especially in many highly populated regions of the world (Kaldellis \& Kondili 2007). Coupling flood control and urban stormwater runoff management with an alternative water supply, rainwater harvesting systems have grown in popularity and become an increasingly important part of urban water systems in Australia, Germany, China, and the USA (Herrmann \& Hasse I997; Coombes et al. 2000; Zhang et al. 2009; Mendez et al. 20II).
Rainwater can be harvested through storage devices or indirectly through groundwater recharge by means of concave green spaces, pervious brick pavements, and so on. The harvested rainwater is then used for potable and nonpotable purposes as a supplementary supply in urban areas to save potable water consumption (Mendez et al. 20II). Due to the difficulties and expenses associated with monitoring rainwater harvesting systems, models are often utilized to determine the feasibility of rainwater harvesting at a given location, design the optimal storage tank volume, evaluate the performance of a rainwater harvesting system, and assess the benefits associated with a rainwater harvesting system (Kim \& Yoo 2009; Su et al. 2009; Basinger et al. 2010; Jones \& Hunt 20I0; Zhang et al. 2012).

Rainwater harvesting potential in an urban area is dependent on the land use pattern and climatic conditions as well as soil and plant characteristics (Boers I994; Li 
et al. 2004). In most research, the rainwater runoff volume was commonly calculated based on the runoff coefficient method or the soil conservation service (SCS)-curve number $(\mathrm{CN})$ method. However, the classical methods encounter difficulties in correctly simulating the response of urban catchments to moderate rainfall events (Rodriguez et al. 2000), as the runoff coefficients vary considerably for different landscapes and rainfall events (Merz \& Blöschl 2009). Estimation of infiltration of pervious areas can be seriously distorted while using the average rainfall without consideration of rainfall duration and intensity characteristics. It is, therefore, inadequate to use the runoff coefficient method to estimate the rainwater harvesting potential (Kahinda et al. 2008). In the SCS curve method, the values of $\mathrm{CN}$ are significantly sensitive to the runoff calculation precision (Boughton I989). Therefore, it is necessary to develop more accurate methods to assess the potential for rainwater availability in urban areas.

In this study, we developed a water mass balance approach coupling urban hydrological cycle processes, and used minute-interval rainfall data to calculate the potential volume of rainwater availability of rooftops, hard ground surfaces, and green land under different rainwater harvesting practices. A case study of urban areas inside the 5th Ring Road of Beijing was conducted. The calculated rainwater availability potential (RAP) represents the maximum available rainwater harvesting volume, whereas the practical available volume may be much less, due to the limitations of harvesting efficiency and engineering feasibility. The method and results can provide scientific support for city managers to design reasonable harvesting measures and thus to improve sustainable water management in cities.

\section{MATERIALS AND METHODS}

\section{Study area}

The RAP within the 5th Ring Road of urban areas $\left(668.02 \mathrm{~km}^{2}\right)$ in Beijing, China was assessed. This region has a typical monsoon-influenced semi-humid continental climate with annual mean temperature of $13.1^{\circ} \mathrm{C}$, and annual mean evaporation of about $980 \mathrm{~mm}$. The average annual precipitation (from 1951 to 2008) is $592 \mathrm{~mm}$, and $81.6 \%(483 \mathrm{~mm})$ of the total precipitation occurs in the flood season (June to September). The percentage distribution of the average monthly precipitation is presented in Figure 1.

Beijing is listed among the world's top 10 cities suffering from lack of adequate water resources. The current available water resource per capita is only $134.7 \mathrm{~m}^{3}$ per year (BMBS 20I2), which is about $1 / 20$ of the national average and $1 / 60$ of the world average, indicating that Beijing belongs to an area of extreme water deficit. Groundwater overdraft, low river flows, and water quality degradation have made the water shortage problem more serious. Therefore, the Beijing Municipal Government places a strong emphasis on rainwater collection. According to the Beijing Municipal Water Conservation Office, by the end of 2012, 898 rainwater harvesting projects had been constructed in urban areas, including water-permeable brick pavements of 3.18 million $\mathrm{m}^{3}$, concave green spaces of 2.8 million $\mathrm{m}^{3}$, and rainwater reservoirs of 3.27 million $\mathrm{m}^{3}$. The collected rainwater is commonly used for greenbelt irrigation, car washing and toilet flushing.

\section{Rainfall data}

The duration and intensity of rainfall events significantly influenced the rainwater availability in a given area. The minute intervals of rainfall data for different districts of Beijing are quite scarce. In this study, we selected a year of rainfall data

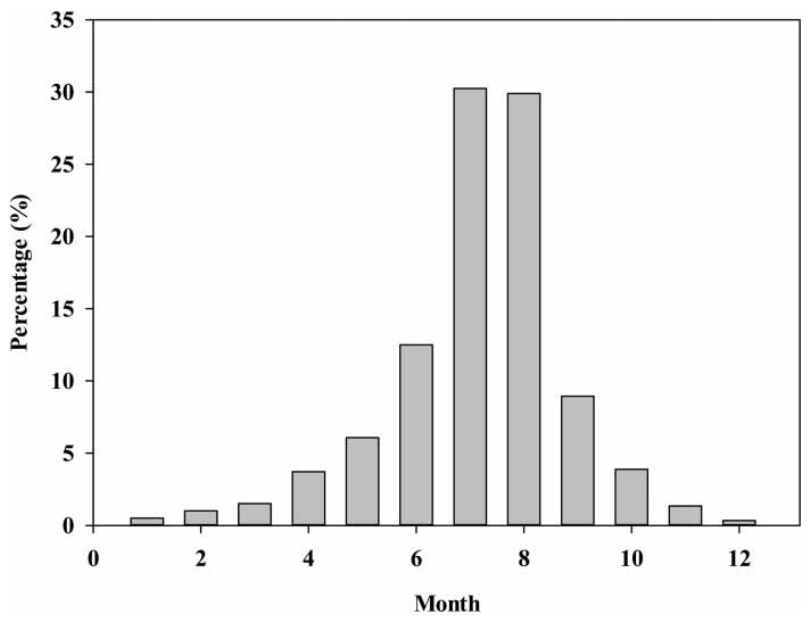

Figure 1 | The distribution percentage of average annual precipitation of Beijing from 1951 to 2008 
with 10-min intervals representing the typical rainfall events for simulation, which approached the average rainfall (592 $\mathrm{mm})$ of the whole city of Beijing. According to the data from Pan et al. (20I0), the variation of multi-annual average rainfall within the urban area of Beijing was about 3\%. The spatial variability of rainfall in the urban area was ignored in this study. The rainfall data with 10-min intervals and daily temperature data in 2013 were obtained from the meteorological station of the Research Center for Eco-Environment Sciences, CAS, Haidian District, Beijing (N40 00'26" , E116 $20^{\prime} 17^{\prime \prime}$ ). The frequency distribution of the rainfall amount is shown in Table 1 . The total rainfall amount from March to October 2013 was 473.9 mm, accounting for $98.5 \%$ of the annual precipitation of $481.2 \mathrm{~mm}$.

\section{Underlying surfaces}

The types and composition of urban underlying surfaces determined the volume of rainwater runoff yield. The data on underlying surface areas were acquired through the interpretation of advanced land observing satellite images (22 October 2009) with a classification accuracy of $94.14 \%$. The rooftops area was acquired from the map of electricity supply to buildings in Beijing. The hard ground surface area equals the interpreted impervious area minus the rooftops area. The different underlying surface areas and percentages within the 5th Ring Road of Beijing are shown in Table 2. About half of the impervious area was rooftops, while the other half was the hard ground surface

Table 1 | Statistics of rainfall events from April to October in 2013

\begin{tabular}{|c|c|c|c|c|c|c|}
\hline & $\leq \mathbf{1} \mathbf{m m}$ & $\begin{array}{l}1- \\
5 \mathrm{~mm}\end{array}$ & $\begin{array}{l}5- \\
10 \mathrm{~mm}\end{array}$ & $\begin{array}{l}10- \\
20 \mathrm{~mm}\end{array}$ & $\begin{array}{l}20- \\
40 \mathrm{~mm}\end{array}$ & $\geq \mathbf{4 0} \mathrm{mm}$ \\
\hline Frequency & 5 & 25 & 9 & 5 & 4 & 3 \\
\hline $\begin{array}{l}\text { Total rainfall } \\
\quad(\mathrm{mm})\end{array}$ & 3.4 & 55.2 & 64.0 & 87.5 & 93.4 & 170.4 \\
\hline $\begin{array}{l}\text { Percentage } \\
(\%)\end{array}$ & 0.73 & 11.64 & 13.50 & 18.46 & 19.71 & 35.96 \\
\hline
\end{tabular}

area including roads, pavements, sidewalks, squares, playgrounds and parking lots. The green land area accounted for nearly one-third of the study area. Bare land, farmland, and water bodies were ignored in the rainwater potential calculation, given that their area was insignificant and runoff/overflow from them was small.

\section{Model approaches}

A mass balance approach was developed to calculate RAP based on the different urban underlying surfaces, and the whole year rainfall data of short time $(10 \mathrm{~min})$ intervals. Three types of urban underlying surfaces were selected: rooftops, hard ground surfaces, and green land. Runoff during the first flush of a storm event bears the highest concentration of pollutants in urban areas ( $\mathrm{Li}$ et al. 2007). The initial flow is abandoned in calculating the available volume of rainwater utilization from rooftops and hard ground surfaces. The model framework is shown in Figure 2.

The volume of rainwater harvesting from rooftops is calculated by rainfall minus the initial loss and the initial split flow. The equation of rainwater availability of rooftops $\left(R_{\mathrm{F}}, \mathrm{m}^{3}\right)$ can be expressed as

$R_{\mathrm{F}}=\left(P-L_{\mathrm{F}}-B_{\mathrm{F}}\right) \times A_{\mathrm{F}}$

where $P$ is rainfall $(\mathrm{mm}), L_{\mathrm{F}}$ is the initial loss of rooftops (mm), $B_{\mathrm{F}}$ is the initial split flow of rooftops (mm) and $A_{\mathrm{F}}$ is the rooftops area $\left(\mathrm{m}^{2}\right)$.

Similarly, the equation used for calculating the rainwater availability of hard ground surfaces $\left(R_{\mathrm{H}}, \mathrm{m}^{3}\right)$ is calculated as

$$
R_{\mathrm{H}}=\left(P-L_{\mathrm{H}}-B_{\mathrm{H}}\right) \times A_{\mathrm{H}}
$$

where $L_{\mathrm{H}}$ is the initial loss of hard ground surfaces $(\mathrm{mm})$, $B_{\mathrm{H}}$ is the initial split flow of hard ground surfaces $(\mathrm{mm})$ and $A_{\mathrm{H}}$ is the area of hard ground surfaces $\left(\mathrm{m}^{2}\right)$.

Table 2 | The underlying surface of the urban area of Beijing (inside the 5th Ring Road)

\begin{tabular}{lcccccc} 
Surface types & Rooftops & Hard ground surface & Green land & Bare land & Farmland & Water bodies \\
\hline Area $\left(\mathrm{km}^{2}\right)$ & 224.12 & 203.32 & 186.56 & 9.54 & 31.91 \\
Percentage $(\%)$ & 33.65 & 30.53 & 28.01 & 1.43 & 4.57 & 1.59 \\
\hline
\end{tabular}




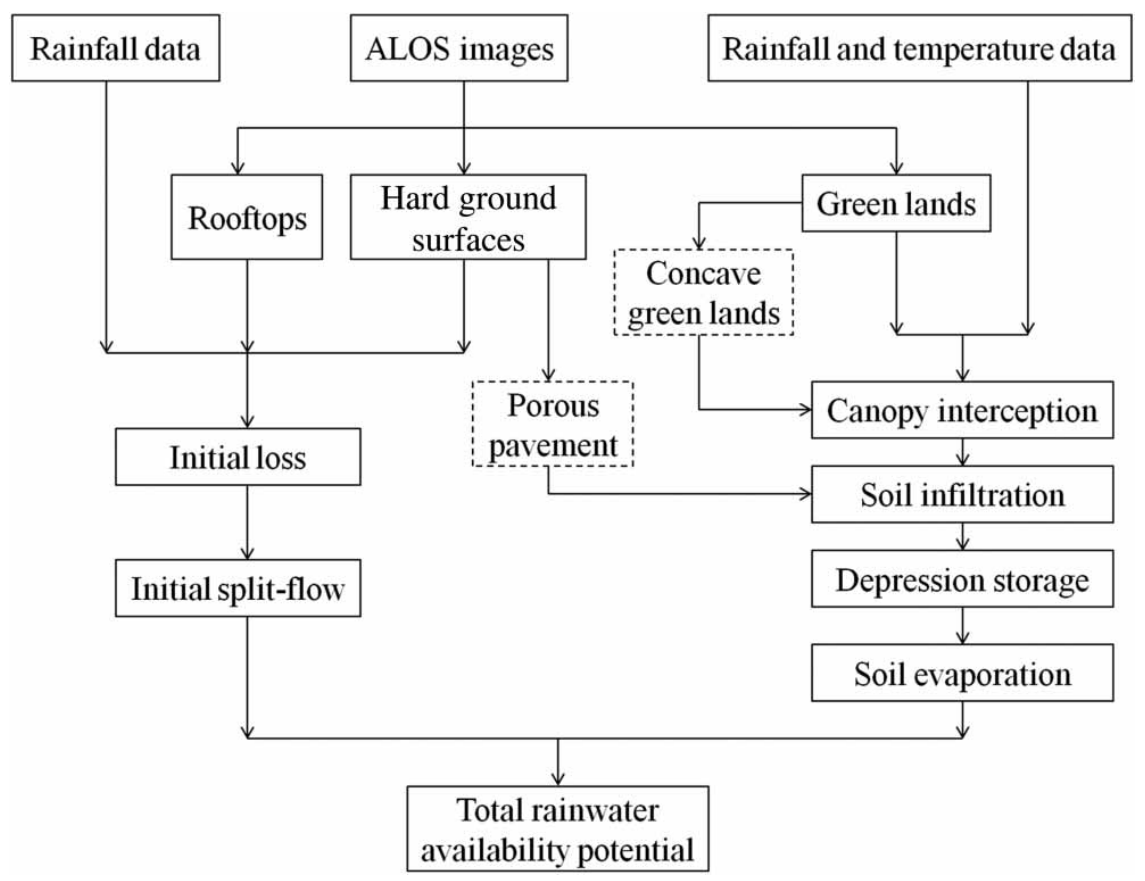

Figure 2 Flow chart of calculating RAP and infiltration increase.

The interception and infiltration processes can significantly affect runoff from green land, especially during small rain events. When the rainfall exceeds the retention capacity of green land, the overflow runs out to hard ground surfaces and combines with the runoff draining into reservoirs. Thus, the equation to calculate the overflow from the green land $\left(R_{\mathrm{G}}, \mathrm{m}^{3}\right)$ is

$R_{\mathrm{G}}=(P-C-F-D-E) \times A_{\mathrm{G}}$

where $C$ is the interception by the vegetation canopy $(\mathrm{mm}), F$ is the infiltration into soil (mm), $D$ is the depression storage of green land (mm), $E$ is the evaporation of soil (mm) and $A_{\mathrm{G}}$ is the area of green land $\left(\mathrm{m}^{2}\right)$. The equation and parameters used for calculation of these terms are summarized in Table 3.

The model continuously simulates RAP of the rooftops, hard ground surfaces, and green land of all rain events in a year. The RAP of the study area is the sum of the available volume of rainwater utilization of these three types of surface.

To increase stormwater runoff mitigation potential of rainwater harvesting systems, infiltration facilities such as concave green land and porous brick pavements can be added to the system.
Table 3 Equations used for calculation of the overflow from green land ${ }^{a}$

\begin{tabular}{ll} 
Variables & Equations \\
\hline Interception & $C=S_{\mathrm{L}} \times L A I$ \\
Infiltration & $F=K_{\mathrm{s}} t+S_{\mathrm{f}} \Delta \theta \ln \left(1+F / S_{\mathrm{f}} \Delta \theta\right)$ \\
Depression & $D=S d_{\max }\left(1-\exp \left(-P C / S d_{\max }\right)\right)$ \\
Evaporation & $E=E T\left(1-W_{\mathrm{r}} / W_{\max }\right)$ \\
& $E T=0.0023 \times\left(R A_{\max } / \lambda\right)\left(T_{\max }-T_{\min }\right)^{0.5}\left(T_{\mathrm{av}}+17.8\right)$
\end{tabular}

Where $S_{\mathrm{L}}$ denotes specific leaf storage $(\mathrm{mm}), L A l$ is canopy leaf area index, $K_{\mathrm{S}}$ is the saturated hydraulic conductivity $(\mathrm{mm} / \mathrm{min}), t$ is the time intervals of rainfall $(\mathrm{min}), S_{\mathrm{f}}$ is suction at wetting front $(\mathrm{mm}), \Delta \theta$ is the soil water deficit (\%), which is the difference between saturated water content and the initial water content, $F$ is cumulative depth of infiltration ( $\mathrm{mm}$ ), $S d_{\max }$ is depression storage capacity of the green land $(\mathrm{mm}), P C$ is the accumulated residual rainfall $(\mathrm{mm})$, which represents rainfall minus interception and infiltration, $E T$ is the potential evaporation $(\mathrm{mm}), W_{\mathrm{r}}$ is unsaturated water storage $(\mathrm{mm}), W_{\max }$ is maximum allowable water storage $(\mathrm{mm}), R A_{\max }$ is the extraterrestrial radiation of the surface related to latitude $\left(\mathrm{MJ} / \mathrm{m}^{2}\right), \lambda$ is the latent heat of vapor $(\mathrm{MJ} / \mathrm{kg})$ which is usually $2.45 \mathrm{MJ} / \mathrm{kg}, T_{\max }$ is the maximum daily temperature ( $\mathrm{C}$ ), $T_{\min }$ is the minimum daily temperature $\left({ }^{\circ} \mathrm{C}\right), T_{\mathrm{av}}$ is the average daily temperature ( $\mathrm{C}$ ).

The overflow from concave green land $\left(R_{\mathrm{c}}, \mathrm{m}^{3}\right)$ is calculated by

$R_{\mathrm{c}}= \begin{cases}\left(P_{\mathrm{c}}+q-f_{\mathrm{c}}-\frac{1}{2} h_{\mathrm{c}}\right) A_{\mathrm{G}} & P_{\mathrm{c}}+q-f_{\mathrm{c}}>\frac{1}{2} h_{\mathrm{c}} \\ 0 & P_{\mathrm{c}}+q-f_{\mathrm{c}} \leq \frac{1}{2} h_{\mathrm{c}}\end{cases}$ 
where $P_{\mathrm{c}}$ is the net rainfall after canopy interception, $q$ is the storage level on the concave green land of the previous time interval $(\mathrm{mm}), f_{\mathrm{c}}$ is the infiltration of the concave green land $(\mathrm{mm})$, and $h_{\mathrm{c}}$ is the depth of concave green land $(\mathrm{mm})$.

The runoff from the porous brick pavement $\left(R_{\mathrm{p}}, \mathrm{m}^{3}\right)$ is calculated by

$R_{\mathrm{p}}= \begin{cases}\left(P-\eta \Delta t+F_{\mathrm{p}}-H_{\mathrm{p}}\right) \beta A_{\mathrm{p}} & P-\eta \Delta t+F_{\mathrm{p}}>H_{\mathrm{p}} \\ 0 & P-\eta \Delta t+F_{\mathrm{p}} \leq H_{\mathrm{p}}\end{cases}$

where $\eta$ is the infiltration rate of subgrade soil ( $\mathrm{mm} / \mathrm{min}), F_{\mathrm{p}}$ is the accumulated water volume contained in subgrade soil $(\mathrm{mm}), H_{\mathrm{p}}$ is the maximum capacity of the porous brick pavement ( $\mathrm{mm}), \beta$ is the proportion of hard ground surface paved with the porous brick pavement and $A_{\mathrm{p}}$ is the area of hard ground surface.

\section{Parameters for the calculations}

The parameters used for calculating RAP used the values found in literature (Table 4). Since Beijing is situated on a plain, the surface terrain is assumed to be flat when selecting parameter values.

\section{RESULTS AND DISCUSSION}

\section{Total RAP}

The RAP of each surface was calculated, using the model with defined parameters, rainfall data, temperature data, and interpreted underlying surface. The simulated results are summarized in Table 5.

Table 4 | The parameter values and their sources for model calculations

\begin{tabular}{|c|c|c|c|c|}
\hline Parameter & Notation & Value & Unit & Source \\
\hline Saturated hydraulic conductivity & $K_{\mathrm{s}}$ & 0.144 & $\mathrm{~mm} / \mathrm{min}$ & Xie et al. (I998) \\
\hline Soil water deficit & $\Delta \theta$ & 14.348 & $\%$ & Xie et al. (I998) \\
\hline Wetting front suction & $S_{\mathrm{f}}$ & 69.696 & $\mathrm{~mm}$ & Fu et al. (2002) \\
\hline Maximum allowable water storage & $W_{\max }$ & 121.2 & $\mathrm{~mm}$ & Ren et al. (200o) \\
\hline Leaf area index & $L A I$ & 3.85 & - & $\mathrm{Su} \& \mathrm{Xie}(2003)$ \\
\hline Special leaf storage & $S_{\mathrm{L}}$ & 0.2 & $\mathrm{~mm}$ & Wang et al. (2008) \\
\hline Initial loss of rooftops & $L_{\mathrm{F}}$ & 2 & $\mathrm{~mm}$ & Lange et al. (20II) \\
\hline Initial loss of hard ground surfaces & $B_{\mathrm{F}}$ & 3 & $\mathrm{~mm}$ & $\mathrm{Xu}(\mathrm{Ig98})$ \\
\hline Depression storage of green land & $S d_{\max }$ & 3.5 & $\mathrm{~mm}$ & Chen \& Adams (2007) \\
\hline Initial split flow of rooftops & $L_{\mathrm{H}}$ & 2 & $\mathrm{~mm}$ & Che et al. (2007) \\
\hline Initial split flow of hard ground surfaces & $B_{\mathrm{H}}$ & 5 & $\mathrm{~mm}$ & Che et al. (2007) \\
\hline Infiltration rate of subgrade soil & $H$ & 0.3 & $\mathrm{~mm} / \mathrm{min}$ & Wang (2007) \\
\hline Maximum capacity of porous brick pavement & $H_{\mathrm{p}}$ & 32.86 & $\mathrm{~mm}$ & Wang (2007) \\
\hline
\end{tabular}

Table 5 | Water mass balance for different surface types (million $\left.\mathrm{m}^{3}\right)^{\mathrm{a}}$

\begin{tabular}{|c|c|c|c|c|c|c|c|c|}
\hline \multirow[b]{2}{*}{ Composition } & \multirow[b]{2}{*}{ Rainwater availability potential } & \multirow[b]{2}{*}{ Rainwater harvest ratio (\%) } & \multicolumn{6}{|c|}{ Ratio of rainfall losses to rainfall (\%) } \\
\hline & & & $\boldsymbol{L}$ & B & c & $\boldsymbol{F}$ & D & $\boldsymbol{E}$ \\
\hline Rooftops & 74.55 & 70.20 & 13.08 & 16.72 & - & - & - & - \\
\hline Hard ground surfaces & 52.26 & 54.25 & 16.46 & 29.29 & - & - & - & - \\
\hline Green land & 27.67 & 31.30 & - & - & 3.74 & 51.39 & 3.19 & 10.38 \\
\hline Total & 154.49 & 53.09 & 10.23 & 15.80 & 1.14 & 15.61 & 0.97 & 3.16 \\
\hline
\end{tabular}

${ }^{a} L$ is the initial loss, $B$ is the initial split flow, $C$ is the interception by vegetation canopy, $F$ is the infiltration into soil, $D$ is the depression storage of green land, $E$ is the evaporation of soil. 
The total RAP of the study area in 2013 was about 154.49 million $\mathrm{m}^{3}$. About $53 \%$ of rainwater could be effectively harvested for use. Rooftop surfaces had the largest rainwater harvest ratio, with $70.20 \%$ of rainfall from the rooftops being available to use, that is, the rooftop surface accounting for one-third of the underlying surface contributed $48.26 \%$ of the total RAP.

With a greater initial loss and a much greater initial split flow than those of the rooftops, the rainwater harvest ratio of the hard ground surfaces dropped to $54.25 \%$. With a similar area to the rooftops, the hard ground surfaces had RAP of 52.26 million $\mathrm{m}^{3}, 22.29$ million $\mathrm{m}^{3}$ less than that from the rooftops, and it contributed $33.83 \%$ of the total RAP.

The RAP of green land was much lower than that of rooftops and hard ground surfaces. In green land, most of the rainfall infiltrated into the soil (accounting for $51.39 \%$ ), and only $31.30 \%$ was available to use. The remainder was lost through interception, depression storage, and evaporation. Overall, it provided 27.67 million $\mathrm{m}^{3}$ of RAP, contributing $17.91 \%$ of the total RAP.

In reality, the initial loss of rooftops and hard ground surfaces, and the depression storage of green land may be slightly decreased when considering the slopes of these areas. However, the water mass balance results in Table 5 indicate that the initial loss and depression storage account for about $15 \%$ and $3 \%$ of rainwater availability potential, respectively. Therefore, it implies that the impact of a small change in parameter values on rainwater availability potential is minuscule based on linear correlation.

The model was simulated by classical formulae of water mass balance and hydrological processes, thus the model accuracy could be trusted. Although it is hard to validate the model performance directly in a large-scale urban area, the runoff ratios calculated by the simulation outcomes are close to other those of other research in China. For example, based on the long-term (58 years) rainfall data and large-scale topographic map data, the average runoff coefficient of the urban area of Nanjing was calculated as 0.66 (Zhang et al. 20I2), and the resultant runoff ratio of rooftops in Beijing was 0.62 (Zhang et al. 2009). The results indirectly validate the conclusion that the model predictions are in a reasonable range.

Based on the population density data from the China National Bureau of Statistics and water consumption data from the Standard of Water Quantity for Cities' Residential
Use (Ministry of Construction of China, 2006), the total RAP is equivalent to $64.33 \%$ of annual domestic water consumption, and rooftop RAP alone can provide $39.84 \%$ of annual water consumption for toilet flushing for the residents within the study area $\left(187.13\right.$ million $\left.\mathrm{m}^{3}\right)$. Therefore, rainwater harvesting and utilization in the urban area of Beijing has great potential to substitute for potable water consumption.

\section{Increasing stormwater runoff mitigation potential through infiltration facilities}

Rainwater harvesting systems for hard ground surfaces and green land are often confined by limited urban spaces, costs, and water quality (Zuo et al. 2009). Indirect use of rainwater from these areas can be achieved through infiltration facilities such as concave green land construction and porous brick pavements. These facilities can increase the infiltration capacity, and further expand water storage in the underlying soil or recharge groundwater, and alleviate stormwater runoff and street water logging.

Significant runoff reduction and infiltration increase were observed after the conversion of green land and hard ground surfaces (Table 6). Under the rain conditions of 2013, concave green land with a depth of $5 \mathrm{~cm}$ decreased the ratio of runoff to $12.41 \%$, and increased the amount of rainfall that infiltrated into the soil to $18.89 \%$. Of the infiltrated rainfall, $70.28 \%$ was either subsequently used by plants or recharged the groundwater. Moreover, the overflow from cost-saving storage tanks of rooftops can be drained into concave green spaces to maximize the infiltration of concave green land. The hard ground surfaces paved with porous bricks decreased the ratio of runoff to $40.80 \%$, and increased the infiltration ratio to $55.69 \%$. Therefore, the infiltration facilities can effectively increase the stormwater runoff mitigation potential and groundwater recharge of rainwater harvesting systems. Other benefits

Table 6 | The ratios of stormwater runoff and of infiltration to rainfall for concave green land and for porous brick pavements

\begin{tabular}{lll} 
Surface types & Ratio of runoff (\%) & Ratio of infiltration (\%) \\
\hline Concave green land & 12.41 & 70.28 \\
Porous brick pavement & 40.80 & 55.69 \\
\hline
\end{tabular}


such as first flush diversion and water quality improvement can also be expected from stormwater runoff reduction.

\section{Effect of rainfall characteristics on RAP}

Changes of rainfall characteristics may significantly affect the RAP for a given study area. The rainfall amount determines the volume of rainwater runoff, and the rainfall intensity affects the ratio of runoff to rainfall of green land as the soil infiltration rate is controlled by rainfall intensity.

The effect of rainfall amount on RAP was investigated by comparing the RAP in cases where the total rainfall amount in 2013 increased by 10\%, 20\%, 30\%, 40\% and $50 \%$, respectively, while the rainfall frequency remained unchanged. The effect of rainfall increase by different amounts on the RAP for different surfaces are shown in Table 7 and Figure 3(a). As expected, the rainfall amount can substantially impact the estimated RAP. Therefore, longer records of rainfall data can reduce the variation of RAP estimation.

Table 7 | The effect of changes in rainfall amount on total RAP

\begin{tabular}{lrlrlr} 
& \multicolumn{6}{c}{ Rainfall increase percent } & & \\
\cline { 2 - 6 } & \multicolumn{1}{c}{$\mathbf{1 0 \%}$} & \multicolumn{1}{c}{$\mathbf{2 0 \%}$} & \multicolumn{1}{c}{$\mathbf{3 0 \%}$} & \multicolumn{1}{c}{$\mathbf{4 0 \%}$} & \multicolumn{1}{c}{$\mathbf{5 0 \%}$} \\
\hline Total RAP (million $\mathrm{m}^{3}$ ) & 176.74 & 199.46 & 222.48 & 245.78 & 269.46 \\
Increased percent $(\%)$ & 14.40 & 29.11 & 44.01 & 59.09 & 74.42 \\
\hline
\end{tabular}

The effect of rainfall intensity on RAP was compared under a constant annual rainfall amount with different intensity distributions. All the rain events in 2013 were classified into three types according to the rainfall intensity. Light rain (when the rainfall intensity is less than $2.5 \mathrm{~mm}$ per hour); moderate rain (the rainfall intensity is between 2.5 and $7.6 \mathrm{~mm}$ per hour); and heavy rain (the rainfall intensity is more than $7.6 \mathrm{~mm}$ per hour), according to the Glossary of Meteorology (Glickman 2000). Assuming the total annual rainfall amount was constant, all the rain events were changed into the three rainfall types, respectively. These rainfall data with different intensity distributions were used as inputs for model calculations. The simulated results are shown in Figure 3(b). The total RAP was 126.82 million $\mathrm{m}^{3}$, 145.02 million $\mathrm{m}^{3}$, and 174.46 million $\mathrm{m}^{3}$, and the RAP of green land was 0 million $\mathrm{m}^{3}, 18.20$ million $\mathrm{m}^{3}$, and 47.64 million $\mathrm{m}^{3}$, respectively, under light, moderate, and heavy rain scenarios. The RAP of green land under heavy rain was more than twice that under moderate rain. Compared with the total RAP in 2013, the potential decreased by $17.91 \%$ and $6.13 \%$, respectively, under light and moderate rain scenarios, and increased by $12.93 \%$ under the heavy rain scenario. Therefore, due to the large seasonal variation of rainfall intensity, rainfall data with small time intervals can improve the accuracy of RAP prediction and the reliability of rainwater harvesting system design.
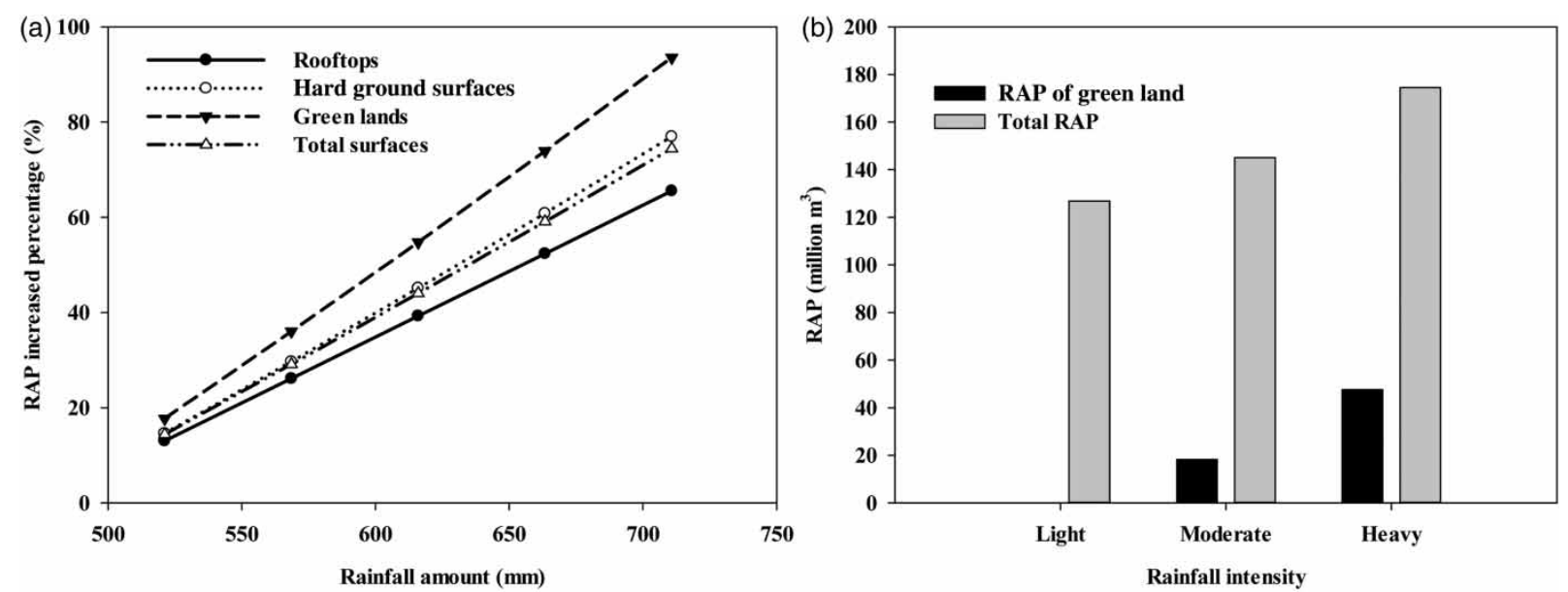

Figure 3 | (a) The RAP change under increased rainfall amounts and (b) the RAP change under different rainfall intensities. 


\section{CONCLUSIONS}

The objective of this study was to assess the RAP of the Beijing urban area based on annual rain events with data at 10-min intervals, and the water mass balance approach coupling urban hydrological processes. The RAP assessment was made including aspects of potable water substitution, stormwater runoff reduction and infiltration increase. The total RAP for non-potable uses can partly substitute the potable water sources and can significantly reduce potable water demand. Rooftops have the largest rainwater harvest ratio, and thus are the best surface for rainwater harvesting by installing tanks and cisterns. Owing to the compact and limited urban space, more concave green land and porous pavements for rainwater infiltration are proposed to combine with rainwater harvesting systems to mitigate stormwater runoff and increase rainwater retention in urban areas. It was found that the model inputs, the rainfall amount and intensity, can significantly impact RAP. The rainfall data with long record periods and small time intervals can improve the accuracy of RAP prediction, and the reliability of rainwater harvesting system design.

The enormous rainwater availability potential and multiple benefits provided by rainwater harvesting are exhibited. The local government urgently needs to put in place some active measures to facilitate rainwater harvesting and utilization practices. First, the related laws and regulations, economic incentive policies, and local engineering technical norms for rainwater harvesting need to be quickly promulgated to guide the rainwater harvesting practices. Second, the government should encourage enterprises to participate in technical research and device production/construction for rainwater harvesting. Furthermore, the public awareness of rainwater harvesting should be popularized through scientific propaganda and training courses to encourage more citizens to harvest and use rainwater.

\section{$\overline{\text { ACKNOWLEDGEMENTS }}$}

We are thankful for the financial support of the National Natural Science Foundation of China (\#41271501) and the National Science \& Technology Pillar Program during the Twelfth Five-year Plan Period (\#2012BAC13B04) to this research. Dr Lei Yao of the Research Center for EcoEnvironmental Sciences, Chinese Academy of Sciences, is acknowledged for his warm-hearted assistance in data collection.

\section{REFERENCES}

Aladenola, O. O. \& Adeboye, O. B. 20Io Assessing the potential for rainwater harvesting. Water Resources Management 24 (10), 2129-2137.

Apostolidis, N. \& Hutton, N. 2006 Integrated water management in brownfield sites - more opportunities than you think. Desalination 188 (1), 169-175.

Basinger, M., Montalto, F. \& Lall, U. 20Io A rainwater harvesting system reliability model based on nonparametric stochastic rainfall generator. Journal of Hydrology 392 (3), 105-118.

BMBS (Beijing Municipal Bureau of Statistics) 20I2 Beijing Statistical Yearbook. China Statistics Press, Beijing, China (in Chinese).

Boers, T. M. 1994 Rainwater Harvesting in Arid and Semi-Arid Zones. International Institute for Land Reclamation and Improvement Wageningen, The Netherlands. http://www. samsamwater.com/library/Rainwater_Harvesting_in_Arid_ and_Semi-Arid_Zones.pdf.

Boughton, W. I989 A review of the USDA SCS curve number method. Soil Research 27 (3), 511-523.

Che, W., Zhang, W., Li, J.-Q., Meng, G.-H. \& Wang, H.-L. 2007 Initial split-flow control of urban rainwater runoff pollution. China Water and Wastewater 23, 1 (in Chinese).

Chen, J. \& Adams, B. J. 2007 Development of analytical models for estimation of urban stormwater runoff. Journal of Hydrology 336 (3):458-469.

Coombes, P. J., Argue, J. R. \& Kuczera, G. 2000 Figtree Place: a case study in water sensitive urban development (WSUD). Urban Water 1 (4), 335-343.

Fu, S.-H., Liu, B.-Y., Wu, J.-D. \& Duan, S.-H. 2002 Study on runoff calculation method in Beijing mountainous area. Scientia Geographica Sinica 22 (5), 604-609 (in Chinese).

Glickman, T. 2000 AMS Glossary of Meteorology. CD, 2nd edn, Boston, USA. http://glossary.ametsoc.org/wiki/Rain.

Herrmann, T. \& Hasse, K. 1997 Ways to get water: rainwater utilization or long-distance water supply? A holistic assessment. Water Science and Technology 36 (8), 313-318.

Huong, H. \& Pathirana, A. 2013 Urbanization and climate change impacts on future urban flooding in Can Tho city, Vietnam. Hydrology and Earth System Sciences 17 (1), 379-394.

Jones, M. P. \& Hunt, W. F. 2010 Performance of rainwater harvesting systems in the southeastern United States. Resources, Conservation and Recycling 54 (10), 623-629.

Kahinda, J. M., Lillie, E., Taigbenu, A., Taute, M. \& Boroto, R. 2008 Developing suitability maps for rainwater harvesting in South Africa. Physics and Chemistry of the Earth, Parts A/B/C 33 (8), 788-799. 
Kaldellis, J. \& Kondili, E. 2007 The water shortage problem in the Aegean archipelago islands: cost-effective desalination prospects. Desalination 216 (1), 123-138.

Kim, K. \& Yoo, C. 2009 Hydrological modeling and evaluation of rainwater harvesting facilities: case study on several rainwater harvesting facilities in Korea. Journal of Hydrologic Engineering 14 (6), 545-561.

Konrad, C. P. \& Booth, D. B. 2005 Hydrologic changes in urban streams and their ecological significance. In: Effects of urbanization on stream ecosystems, L. R. Brown, R. H. Gray, R. M. Hughes \& M. R. Meador (eds), American Fisheries Society, Bethesda, MD, USA, pp. 157-177.

Lange, J., Husary, S., Gunkel, A., Bastian, D. \& Grodek, T. 2oп Potentials and limits of urban rainwater harvesting in the Middle East. Hydrology and Earth System Sciences Discussions 8 (6), 10369-10396.

Li, X.-Y., Xie, Z.-K. \& Yan, X.-K. 2004 Runoff characteristics of artificial catchment materials for rainwater harvesting in the semiarid regions of China. Agricultural Water Management 65 (3), 211-224.

Li, L.-Q., Yin, C.-Q., He, Q.-C. \& Kong, L.-L. 2007 First flush of storm runoff pollution from an urban catchment in China. Journal of Environmental Sciences 19 (3), 295-299.

Mendez, C. B., Klenzendorf, J. B., Afshar, B. R., Simmons, M. T., Barrett, M. E., Kinney, K. A. \& Kirisits, M. J. 20II The effect of roofing material on the quality of harvested rainwater. Water Research 45 (5), 2049-2059.

Merz, R. \& Blöschl, G. 2009 A regional analysis of event runoff coefficients with respect to climate and catchment characteristics in Austria. Water Resources Research 45 (W01405).

Ministry of Construction of China 2006 Engineering Technical Code for Rain Utilization in Building and Subdistrict (GB50400-2006). China Building Industry Press, Beijing, China (in Chinese).

Pan, A.-J., Zhang, S.-H., Chen, J.-G. \& Ding, Y.-Y. 2010 The Research and Application of Comprehensive Utilization Technology of Urban Rainwater. China Waterpub Press, Beijing, China (in Chinese).
Ren, S.-M., Zhou, J.-M., Liu, H. \& Meng, G.-H. 2000 Analyses and calculation of increasing infiltration of rainfall in the soil by using hollow grassland. Journal of China Agricultural University 5, 50-54 (in Chinese).

Rodriguez, F., Andrieu, H. \& Zech, Y. 2000 Evaluation of a distributed model for urban catchments using a 7-year continuous data series. Hydrological Processes 14 (5), 899-914.

$\mathrm{Su}, \mathrm{F}$. \& Xie, Z. 2003 A model for assessing effects of climate change on runoff in China. Progress in Natural Science 13 (9), 701-707.

Su, M.-D., Lin, C.-H., Chang, L.-F., Kang, J.-L. \& Lin, M.-C. 2009 A probabilistic approach to rainwater harvesting systems design and evaluation. Resources, Conservation and Recycling 53 (7), 393-399.

Wang, X.-X. 2007 Assessing the Runoff Intercepting Capacity of Greenbelts of Different Underlying Surfaces in Residential District. Thesis of China Agricultural University, Beijing, China (in Chinese).

Wang, J., Endreny, T. A. \& Nowak, D. J. 2008 Mechanistic simulation of tree effects in an urban water balance model. JAWRA Journal of the American Water Resources Association 44 (1), 75-85.

Xie, Y.-H., Huang, G.-H. \& Zhao, L.-X. 1998 Spatial variability of field soil properties. Journal of China Agricultural University 3 (2), 41-45 (in Chinese).

Xu, X.-Y. I998 Simulation of storm runoff process for an urban plain. Journal of Hydraulic Engineering 8 (8), 34-37 (in Chinese).

Zhang, D., Gersberg, R. M., Wilhelm, C. \& Voigt, M. 2009 Decentralized water management: rainwater harvesting and greywater reuse in an urban area of Beijing, China. Urban Water Journal 6 (5), 375-385.

Zhang, X., Hu, M., Chen, G. \& Xu, Y. 2012 Urban rainwater utilization and its role in mitigating urban waterlogging problems - a case study in Nanjing, China. Water Resources Management 26 (13), 3757-3766.

Zuo, J.-B., Liu, C.-M. \& Zheng, H.-X. 2009 Cost-benefit analysis of urban rainwater harvesting: a case study of Beijing. Resources Science 8, 007 (in Chinese). 